\title{
Vegetation condition index pattern (2002-2007) over I ndian agro-climate regions, using of GIS and SPOT sensor NDVI data
}

\author{
K ishan Singh Rawat*1, A nil K umar M ishra ${ }^{1}$, R akesh K umar ${ }^{2}$ and J itendra Singh ${ }^{2}$ \\ ${ }^{1}$ Water Technology Centre, Indian Agriculture Research Institute, New Delhi-110012, INDIA \\ ${ }^{2}$ Division of Agricultural Physics, Indian Agriculture Research Institute, New Delhi-110012, INDIA \\ *Corresponding author.E-mail: ks_rawat2002@yahoo.com \\ Received: A pril 24, 2012; Revised received: J une 28, 2012; Accepted: September 14, 2012
}

Abstract: This study describes the Vegetation Condition Index in the near-real-time with help of SPOT based Normalized Difference Vegetation Index (NDVI) for Agro climatic-region of India and gave the development pattern in last six year (2002-2007) over the study area of India using decadal time data set from SPOT satellite sensor for 2002-2007 time periods. The each Agro-climatic region of study, $1^{\circ} \times 1^{\circ}$ degree in area, part of India agro-climate regions, has been taken for analysis using remote sensing and Geographical Information System (RS and GIS) methods, SPOT satellite sensor NDVI data, and from processed data set (geo-referenced data set), cut out $1^{\circ} \times 1^{\circ}$ degree of area by preparing a layers representing Agro-climatic region of India as base mapping units (BMU), The results indicated that NDVI index is only water stress over vegetation while $\mathrm{VCI}$ is an appropriate index for vegetation pattern monitoring over study area. As satellite observations provide better spatial and temporal coverage, the $\mathrm{VCl}$ based system will provide efficient tools for management of the improvement of agricultural planning. This system will serve as a prototype in the other parts of the world where ground observations are limited or not available.

Keywords: Droughts, Drought indices, Drought severity, Remote sensing, Vegetation condition index

\section{INTRODUCTION}

Vegetation typically shows the seasonal and annual dynamics. The daily temporal resolution and globe coverage of satellite sensors SPOT makes it possible to monitor vegetation at spatial and temporal resolutions globally. Normalized difference vegetation index (NDVI) data collected by SPOT sensor, have been widely used to study vegetation dynamics on the earth (Malik and Husain, 2008). The NDVI shows patterns of vegetative growth from green-up to senescence by indicating the quantity of actively photosynthesizing biomass on a landscape (Burgan et al., 1996) (Fig. 1, http:// free.vgt.vito.be). Such data allow for the production of maps, which indicate visual greenness and can be extremely valuable to land managers and researchers in determining changes in vegetation over time. The NDVI is the difference of near-infrared and visible red reflectance values normalized over reflectance (Burgan 1993). Specifically,

$$
\text { NDVI }=(N I R-R E D) /(N I R+R E D)
$$

The equation produces values ranging from -1 to 1 . Negative values are indicative of clouds, snow, water and other non vegetated, non-reflective surfaces, while positive values denote vegetated or reflective surfaces (Burgan and Hartford, 1993). And these values (range: -1 to +1 ) now days are used in many drought monitoring tools (VCI) as spatial and temporal changes of drought ISSN : 0974-9411 (Print), 2231-5209 (Online) All Rights Reserved ๑ Applied and Natural Science Foundation www.ansfoundation.org because NDVI product are available on decadal time basis data.

Vegetation condition index (VCI) concept was designed to extract the weather component from NDVI values (Kogan, 1990). The fact is that NDVI represents two environmental signals: ecosystem, which explains longterm changes in vegetation (driven by climate, soils, vegetation type, topography, etc.), and weather (short term), explaining intra and inter-annual variations in each ecosystem in response to weather fluctuations. Because the weather component is much smaller than the ecosystem component, the algorithm was developed to enhance the weather component. This procedure was based on three environmental laws: law-of-minimum, law of tolerance, and the principle of carrying capacity (Hardin 1986). These laws provide the basis for determining the lowest and the highest potentials of an ecosystem's resources in response to the environment. Thus VCI can use as an indicator of the status of the vegetation cover as a function of the NDVI minimum and maximum encountered for a given ecosystem over many years (Liu and Kogan, 1996). It shows, effectively, how close the NDVI of the current month is to the minimum NDVI calculated from the long-term record (Peters et al., 2002, Shin and Kim, 2003 and Shin, 2005).

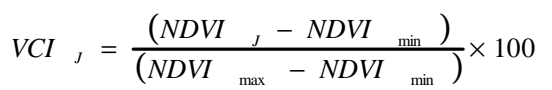


where, NDVI ${ }_{\text {max }}$ andNDVI ${ }_{\text {min }}$ are calculated from the longterm record for that month and $\mathrm{j}$ is the index of the current month. The condition/health of the ground vegetation presented by VCI is measured in percent. The VCI values around 50 per cent reflect a fair vegetation conditions. The VCI values between 50 to 100 per cent indicate optimal or above-normal conditions. At the VCI value of 100 per cent the NDVI value for the month equals to NDVI ${ }_{\max }$. Different degrees of a drought severity are indicated by VCI values below 50 percent.

The VCI value close to zero percent reflects an extremely dry month, when NDVI value is close to its long-term minimum. Consistently low VCI values over several consecutive time intervals may point to drought development/presence.

The main objective for this paper is to assess the vegetation condition pattern coverage by using VCI, at the selected 10 Agro-climatic regions of India by using data set from a temporal set of S10 NDVI images, acquired by SPOT Vegetation instrument.

Study area (A gro-climatic regions of I ndia): The climate of India is essentially a temperate one (Sarkar and Kafatos, 2004). India lies to the north of Equator, so the southern part of India is usually much warmer than the rest of India. Also, water bodies flank India on three sides thus giving the peninsular region maritime climate. The duration of summer in India is from March to June. The temperature in the plains of northern India can go up to $45^{\circ}$ Celsius. The southern region is equally hot. The Monsoon season in India usually lasts from the month of June to that of September. During this time, most of the areas in the country get their share of rainfall. The South West Monsoon enters India through the coast of Kerala and Andaman \& Nicobar Islands and passing Table 1. Agro-climatic regions of Indian sub-continent.

\begin{tabular}{lll}
\hline 1 & Western Himalayan Region & Jammu and Kashmir, Himachal Pradesh, Uttar Pradesh and \\
& & Uttrakhand. \\
2 & Eastern Himalayan Region & Assam Sikkim, West Bengal and all North-Eastern states \\
3 & Lower Gangetic Plains Region & West Bengal. \\
4 & Middle Gangetic Plains Region & Uttar Pradesh, Bihar \\
5 & Upper Gangetic Plains Region & Uttar Pradesh. \\
6 & Trans-Gangetic Plains Region & Punjab, Haryana, Delhi and Rajasthan. \\
7 & Eastern Plateau and Hills Region & Maharastra, Utter Pradesh, Urissa and West Bengal. \\
8 & Central Plateau and Hills Region & Madhya Pradesh, Rajasthan, Uttar Pradesh. \\
9 & Western Plateau and Hills Region & Maharastra, Madhya Pradesh and Rajasthan. \\
10 & Southern Plateau and Hills Region & Andhra Pradesh, Karnataka, Tamil Nadu. \\
11 & East Coast Plains and Hills Region & Urissa, Andhra Pradesh, Tamil Nadu and Pondicheri. \\
12 & West Coast Plains and Ghat Region & Tamil Nadu, Kerala, Goa, Karnatak, Maharastra. \\
13 & Gujarat Plains and Hills Region & Gujarat. \\
14 & Western Dry Region & Rajasthan. \\
15 & The Islands Region & Andman and Nicaobar, Lakshya Dweep. \\
\hline
\end{tabular}

through Mumbai, central India and eastern India, reaches other parts of North and North West India. During the months of October to November, some parts of South India experience rains in the form of the northeastmonsoon. The northern part of India experiences harsh weather conditions with cold wave sweeping almost entire northern regions and central parts of India. The hilly areas experience sub-zero temperature conditions Based on the climatic condition and the agricultural practices, the Indian Subcontinent has been broadly divided into 15 divisions known as the agro-climatic regions (Table 1 and Fig. 2)

Vegetation data: The vegetation data or the Maximum Value Composite NDVI maps were acquired from the VEGETATION program of the SPOT satellite from the site http://free.vgt.vito.be (Yang et al., 1997, Karabulut et al., 2003, Shilong et al., 2004).

The VGT-S10 is a standard vegetation product where VGT stands for vegetation and S10 is the Synthesis of three ten day (Immerzeel et al., 2005). The VGT-S10 products are Maximum Value Composite derived by comparing segments of ten day period pixel by pixel to get the max NDVI value, which would ensure minimum effect of the cloud cover. The VGT-S10 product is acquired for the whole study period and area, starting from X to $\mathrm{Y}$. The VEGETATION Program is developed jointly by France, the European Commission, Belgium, Italy and Sweden. The satellite data for the Program is from SPOT 4 and SPOT 5 using the vegetation instrument (VI) sensor, which was specifically tailored to monitor land surfaces' parameters with a frequency of about once a day on a global basis and a medium spatial resolution of one kilometer (Malingreau and Belward, 1992, Shilong et al., 2004). The overall objective of the "VEGETATION"

Note: Agro-climatic regions 10,12,13,14 and 15 are not taken for study. 


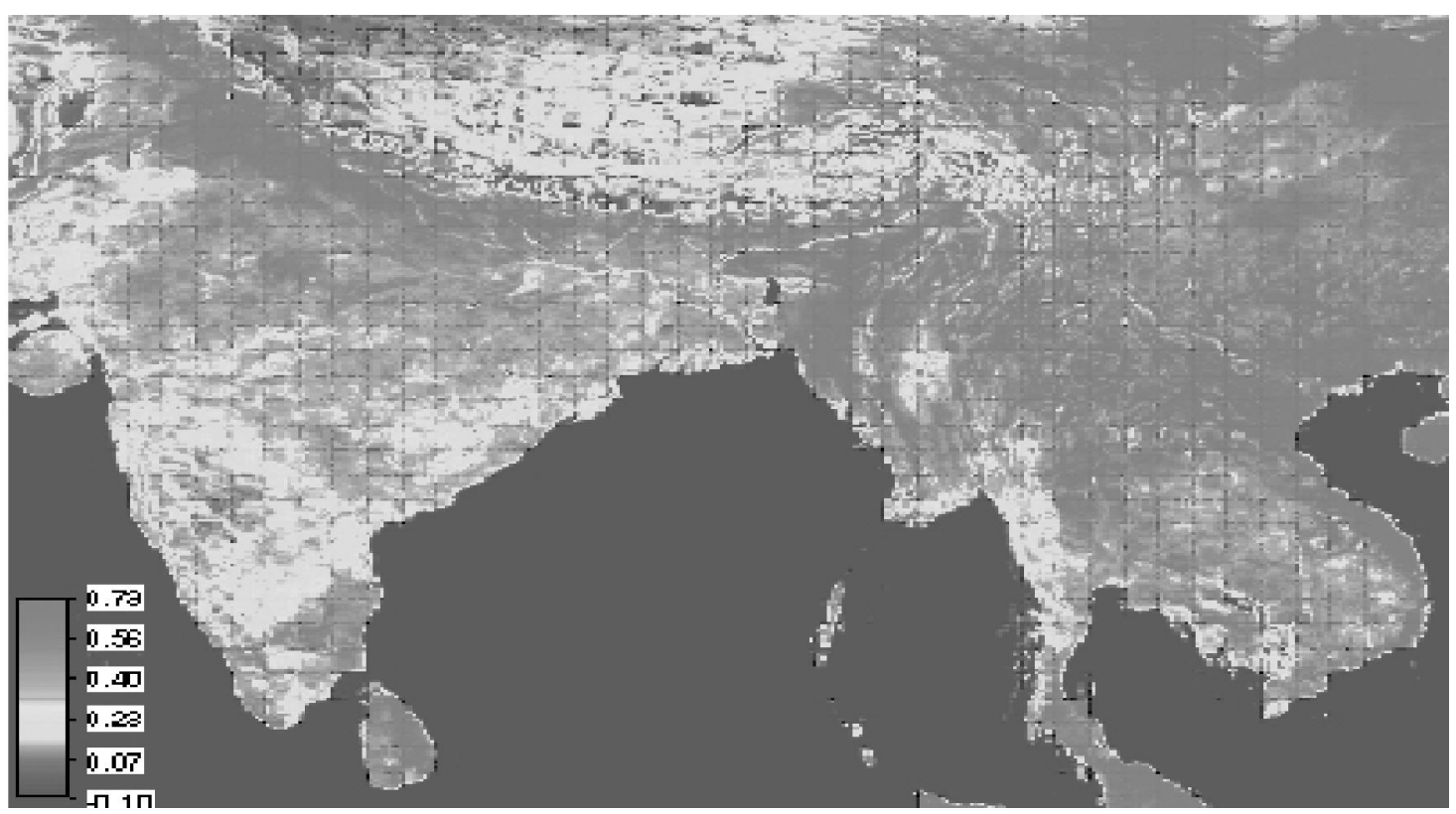

Fig. 1. Spot VGT-S10 product N DVI data (Source: http://free.vgt.vito.be)

system is to provide accurate measurements of basic characteristics of vegetation canopies on an operational basis (Reed et al., 1994, Yang and Merchant, 1998, Zhou et al., 2001). Fig. 1 shows a VGT-S10 product of Maximum value composite NDVI and the Table 2 shows the spectral bands of the vegetation instrument.

Processing of vegetation data: The downloaded data was directly imported into ILWIS via Geogateway option. A coordinate system and georeference using the corner pixel $\left(68^{\circ}-147^{\circ} \mathrm{E} ; 5^{\circ}-55^{\circ} \mathrm{N}\right)$ was created to register the decadal (ten day) Maximum Value Composite (MVC) NDVI images. A conversion equation (Eq. 1) was provided to convert the image value into MVC-NDVI. Using the script option of ILWIS each of the images was converted into MVC-NDVI image. NDVI Value in the original dataset was in digital numbers (DN). So their corresponding NDVI value of the dates was generated from the $\mathrm{DN}$ value using the formula mentioned in VGT user's guide:

$$
\text { NDVI }=\mathrm{DN} \times 0.004-0.01
$$

where, $\mathrm{DN}=$ Digital number

Vegetation condition index (VCI) from normalized difference index (NDVI): Six year maximum NDVI $\left(\mathrm{NDVI}_{\text {max }}\right)$, minimum NDVI $\left(\mathrm{NDVI}_{\text {min }}\right)$ and $\mathrm{NDVI}_{\mathrm{j}}$ is the NDVI of the current month were computed from the NDVI data set.

$\mathrm{VCI}_{1}=\frac{\left(N D V I_{1}-N D V I_{\text {min }}\right)}{\left(N D V I_{\text {max }}-N D V I_{\text {min }}\right)} \times 100$

At 100 percent $\mathrm{VCI}, \mathrm{NDVI}_{\mathrm{j}}=\mathrm{NDVI}_{\max }$ and at zero per cent $\mathrm{VCI}, \mathrm{NDVI}_{\mathrm{j}}=\mathrm{NDVI}_{\min }$. According to Kogan (1997), different degrees of drought severity are indicated by VCI below 50 per cent and VCI of 35 per cent is a threshold for extreme drought (Table 3). Based on this the VCI values obtained were reclassified into drought severity as: 50 per cent to 100 per cent, normal to above normal condition (wet); < 50 per cent to 35 per cent, moderate drought; < 35 to 20 per cent severe drought; < 20 per cent to zero per cent very severe drought. These scales were arbitrarily selected.

A nalysis

G rid gener ation: One $1^{\circ} \times 1^{\circ}$ grid map was created for the ten agro climatic regions by digitizing, using map shown in figure 1 of the agro-climatic regions of India. By cross operation (in ILWIS) between grid map and decadal NDVI map, a table was generated contain values of NDVI of each pixel under each grid of selected agro-climatic region. And by using eq. (2) VCI calculate from NDVI for study area.

Drought analysis using vegetation condition index: The Vegetative Condition Index plots for the different agro climatic regions are given in Fig. 3. The analysis was undertaken for six years starting from 2002 to study the temporal pattern to VCI variation. Persistent low value of the index for a longer duration indicates development of drought conditions (John et al., 1998). Value range between 50 per cent and close to 10 per cent indicates the presence of drought. The analysis to the data for the different regions shows the presence to drought conditions developing in several regions during the study period. In Region 1 (Fig. 3, 1. ACR), it can be seen that during the time period January 2006 to August 2007 the index value was below 50 per cent for a long duration and this attributed to a severe drought condition. Region 2 (Fig. 3, 2. ACR) shows a consistent value of the VCI index with no signs of drought development in any of the study year. The plot shows a normal trend of VCI value throughout the study period with no persistent low values in any year. Region 3 (Fig. 3, 3. ACR) also has 


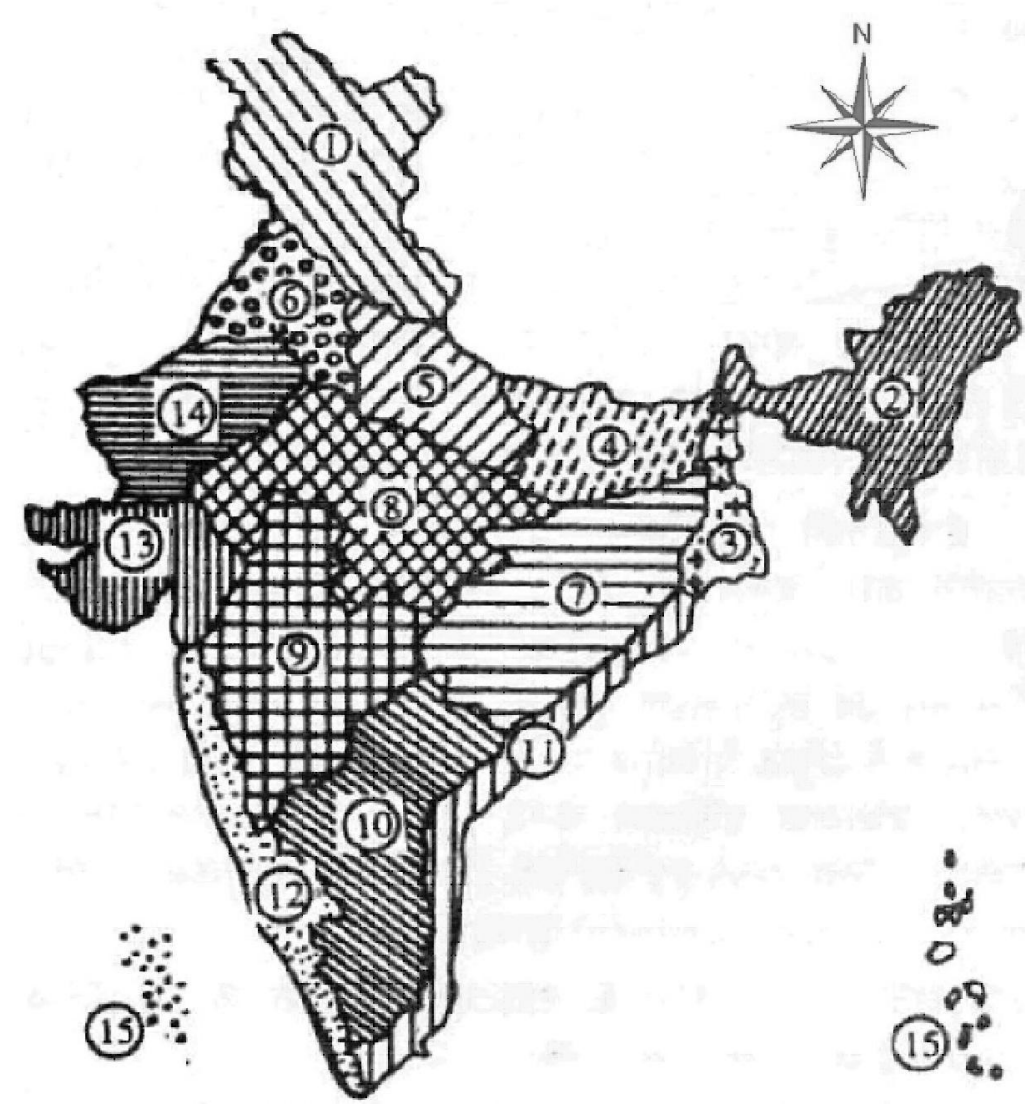

Fig. 2. Study area: Agro-climatic Regions (ACR) of India .

a consistent value of VCI with no indication of drought development in any of the study year. Two spans of drought period can be seen to exist in region 4 (Fig. 3, 4. ACR) ranging from October 2004 to May 2005 and November 2005 to July 2006. Region 5 (Fig. 3, 5. ACR) shows a very good trend of VCI values with a smooth variation throughout the study period and no indication of drought. Region 6 (6. ACR) and 7 (7. ACR) shows a similar variation a $\mathrm{VCI}$ index with a single drought year occurring during October 2004 to 2005 October. A relatively inconsistent variation of $\mathrm{VCI}$ values was seen for Region 8 (Fig. 3, 8. ACR). However, no drought conditions were seen. Region 9 (Fig. 3, 9. ACR) shows a strong pattern of VCI index variation with very high value of index for all the years. Most of the values varied between 75 per cent and 100 per cent showing good vegetative growth period. In Region 11 (Fig. 3, 11. ACR) the VCI index value was seen to stay below 40 per cent value during the period 2006-2007 indicating the development of moderate to severe drought conditions. Calculation

The used indices VCI for the assessment of drought provided a promising tool by integrating remote sensing data and GIS towards decision making. Through VCI analysis in present study it is found that, in agro-climatic region 11 the VCI index value went below 40 per cent value during the period 2006-2007 indicating the development of moderate to severe drought conditions. This study suggests that VCI is better than the NDVI particularly in geographically non-homogeneous areas. Also, VCI values indicate how much the vegetation has advanced or deteriorated in response to weather. This methodological approach is batter then NDVI base vegetation cover monitoring, because NDVI gave only water stress over vegetation cover while VCI provides an indirect measure of moisture conditions of vegetation. Anything that stresses the vegetation including insects, disease, and lack of nutrients will result in decreases in plant growth and therefore lower VCI values (VicenteSerrano 2007). In this study we have assumed that all of

Table 2. Spectral bands of SPOT-VI.

\begin{tabular}{|c|c|}
\hline Spectral band & W avelength $(\mu \mathrm{m})$ \\
\hline B0 (Blue) & $0.43-0.47$ \\
\hline B2 (Red) & $0.61-0.68$ \\
\hline B3 (NIR) & $0.78-0.89$ \\
\hline MIR (SWIR) & $1.58-1.75$ \\
\hline \multicolumn{2}{|c|}{ Table 3. Kogan criteria for vegetation condition (1997). } \\
\hline Kogan criteria & Vegetation condition \\
\hline$>50 \%-100 \%$ & Optimal \\
\hline $50 \%$ & Fair \\
\hline$>35 \%-0 \%$ & Poor \\
\hline
\end{tabular}



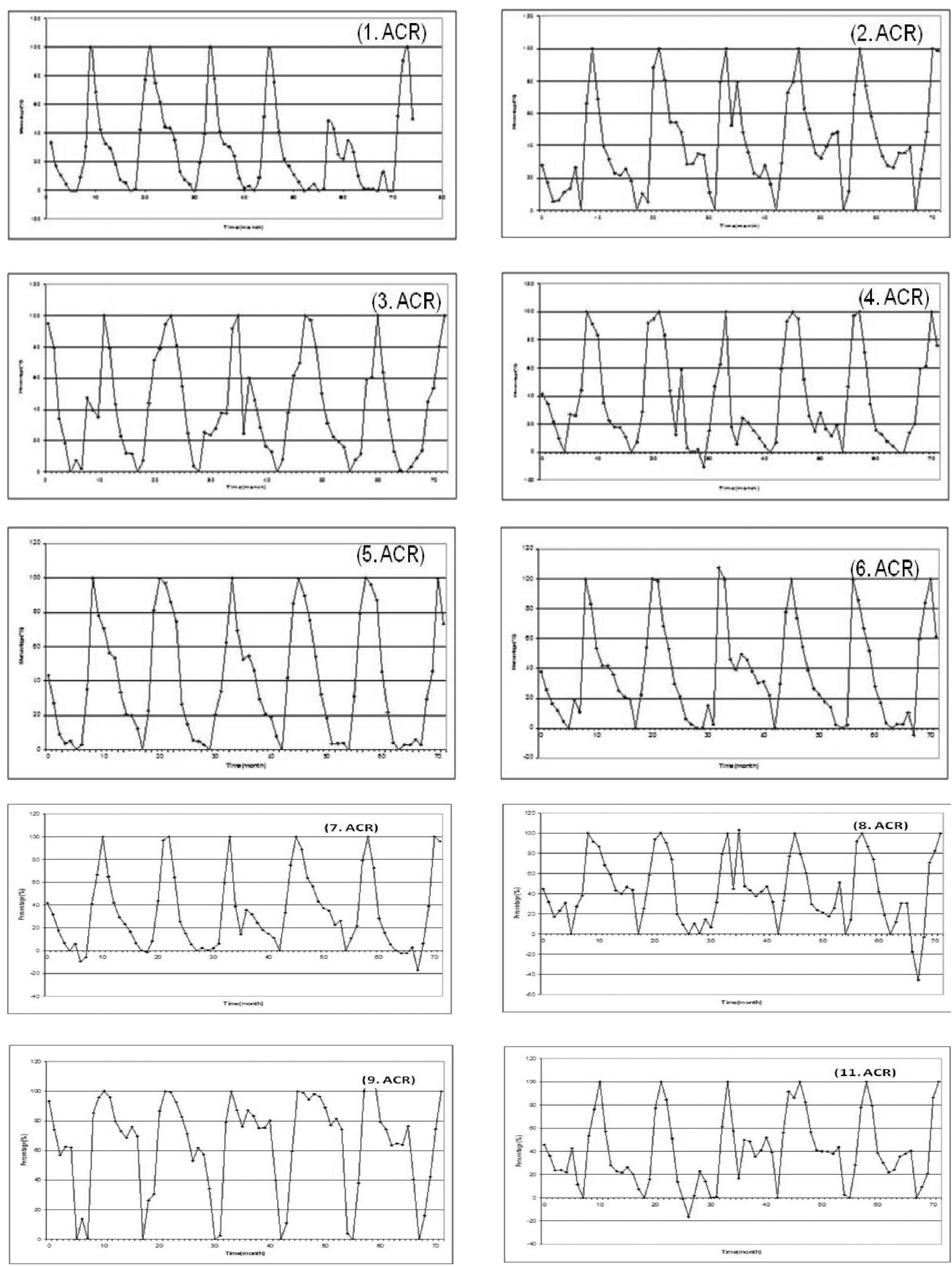

Fig. 3. VCI pattern for Agro climatic region (ACR) of India for duration 2002-2007. 
the variations in the VCI are due to moisture variations because detailed data on insect and disease outbreaks are not available. VCI has both an advantage and a disadvantage. One of the major benefits of the VCI is that it provides continuous spatial coverage and it attempts to directly measure vegetation health. The disadvantage of this approach is that it appears to provide very different information than the traditional meteorological drought indices.

It is very difficult and demonstrates drought conditions using VCI pattern for any climatic region because this index is not a spatially invariant indicator of drought and therefore it cannot be used to compare drought conditions in one part of Indian Agro-climate region with those in another part of Agro-climate region of India. Therefore, the VCI should be employed with caution until its relationship to meteorological drought impacts is better understood

\section{REFERENCES}

Burgan, R. E., Hartford R. A. and Eidenshink J. C. (1996). Using NDVI to assess departure from average greenness and its relation to fire business. Gen. Tech. Rep. INT-GTR333. Ogden, UT: US Department of Agriculture, Forest Service, Intermountain Research Station. pp 8.

Burgan, R. E.and Hartford, R. A. (1993). Monitoring vegetation greenness with satellite data. Gen. Tech. Rep. INT-297. Ogden, UT: US Department of Agriculture, Forest Service, Intermountain Research Station. pp 13.

Hardin, G. (1986). Cultural carrying capacity: A biological approach to human problems. Biological Science, 36:599606.

Immerzeel,W.W., Quiroz, R. A. and Dejong, S. M. (2005). Understanding precipitation patterns and land use interaction in Tibet using harmonic analysis of SPOT VGTS10 NDVI time series. International J ournal of Remote Sensing, 1-15

John, G., Yuan, D., Lunetta, R.S. and Elvidge, C.D. (1998). A change detection experiment using vegetation indices. Photogrammetric Engineering and Remote Sensing, 62:143150.

Karabulut, M. (2003). An Examination of Relationships Between Vegetation and Rainfall Using Maximum Value Composite AVHRR-NDVI Data, Research Article.

Kogan, F. N. (1997). Drought of the late 1980s in the United States as derived from NOAA polar orbiting satellite data. Bulletin of the American M eteological Society, 76: 655668.
Kogan, F.N. (1990). Remote sensing of weather impacts on vegetation in non-homogeneous areas. Inter national J ournal of Remote Sensing, 11:1405-1419.

Liu, W.T. and Kogan, F.N. (1996). Monitoring regional drought using Vegetation Condition Index. International J ournal of Remote Sensing, 17: 2761-2782.

Malik, R. N. and Husain, S.Z. (2008). Linking remote sensing and ecological vegetation Communities: a multivariate approach. Pakistan J ournal of B otany, 40: 337-349.

Malingreau, J.P. and Belward, S.B. (1992). Scale consideration in vegetation monitoring using AVHRR data. Inter national J ournal of Remote Sensing, 13: 2289-2307.

Peters, A. J., Walter-Shea, E. A., Ji, L., Vina, A., Hayes, M, and Svoboda, M.D. (2002). Drought monitoring with NDVIbased standardized vegetation index. Photogrammetric Engineering and Remote Sensing, 68: 71-76.

Reed, B.C., Brown, J.F., Vanderzee, D., Loveland, T.R., Merchant, J.W. and Ohlen, D.O. (1994). Measuring phenological variability from satellite imagery. J ournal of Vegetation Sciences, 5: 703-714.

Sarkar, S. and Kafatos, M. (2004). Interannual variability of vegetation over the Indian sub-continent and its relation to the different meteorological parameters. Remote Sensing of Environment, 90: 268-280.

Shilong, P., Jingyun, F., Wei, J., Qinghua, G., Jinhu, K. and Shu, T.(2004), Variation in a satellite-based vegetation index in relation to climate in China.J ournal of Vegetation Science, 15: $219-226$.

Shin S. H. (2005). Applicability of Multi-temporal NDVI based Drought Index for Drought Monitoring of Korea Peninsula. Inha University Master Paper.

Shin, S.C. and Kim, C. J. (2003). Application of Normalized Difference Vegetation Index for Drought Detection in Korea, Korea Water Resources Association. 36: 839-849. http:// edcimswww.cr.usgs.gov/pub/imswelcome/index.html (EOS Data Gate Way).

Vicente Serrano, S.M. (2007). Evaluating the impact of drought using remote sensing in a Mediterranean, semi-arid region. Natural Hazards, 40: 173-208.

Yang, W., Yang, L. and Merchant, J.W. (1997). An assessment of AVHRR/NDVI ecoclimatological relations in Nebraska, U.S.A. Remote Sensing of Environment, 18: 2161-2180.

Yang, W.L. and Merchant, J.M. (1998). An assessment of AVHRR/NDVI ecoclimatological relations in Nebraska. U.S.A. International J ournal of Remote Sensing, 18: 2161-2180.

Zhou, L. M., Tucker, C. J., Kaufmann, R. K., Slayback, D., Shabanov, N. V. and Myneni, R. B. (2001). Variations in northern vegetation activity inferred from satellite data of vegetation index during 1981 to 1999. J ournal of $\mathrm{G}$ eophysical Research, 106: 20069-20083. 